\title{
Common agents used in parasuicide in Buffalo City
}

K Sukeri, FCPsych (SA)

East London Mental Health Unit, Cecilia Makiwane Hospital, Mdantsane, E Cape

Background. Parasuicide is a serious public health concern. Understanding the methods used will help in developing preventive strategies.

Objective. To investigate the agent(s) used in parasuicide attempts by individuals aged $10-20$ years in Buffalo City Iwhich includes the municipalities of East London, King William's Town and Bhisho in the Eastern Cape).

Method. All referrals for parasuicide to the East London Mental Health Unit, the only mental health facility servicing Buffalo City, for the period January 2006 to December 2008 were analysed with regard to age, agent(s), number of attempts and psychiatric disorder.

Results. Of 1169 patients referred after parasuicide by ingestion of substances, 360 (31\%) were between the ages of 10 and 20 years. Eighty-three per cent were female and $17 \%$ male. Cattle dip was the commonest agent used, followed by amitriptyline.

Conclusion. The study showed that organophosphates were the commonest agent used in parasuicide in Buffalo City and that the incidence of parasuicide was higher in females than in males.

Parasuicide is defined in the World Health Organization (WHO)'s International Classification of Diseases (1992)' as follows: 'Parasuicide is an act with nonfatal outcome, in which an individual deliberately initiates a non-habitual behaviour, that without intervention from others will cause self harm; or deliberately ingests a substance in excess of the prescribed or generally recognised therapeutic dosage and which is aimed at realizing changes which the subject desired via the actual or expected physical consequences.

Parasuicide is a significant predictor of completed suicide., ${ }^{2,3}$ Shaffer ${ }^{4}$ reported that suicide attempts are more common during adolescence. The exact figures for parasuicide among adolescents worldwide are unknown; the WHO estimates the rate to be 40 - 100 times higher than the suicide rate recorded each year. ${ }^{5}$ In 2001 the Centers for Disease Control and Prevention (CDC) reported that suicide was the third leading cause of death among persons aged $10-19$ years in the USA. ${ }^{6}$

The effects of youth suicide go beyond the victim, affecting parents, friends and communities.?

Suicide is a preventable cause of death and therefore merits public health concern. It is therefore necessary to develop programmes to reduce the rates of parasuicide and suicide in the adolescent population. These could include school-based programmes, ${ }^{8}$ early identification and management of mental illness ${ }^{9}$ and reduction of access to methods.

The aim of this study was to determine which agent(s) were used in parasuicide attempts by persons aged $10-20$ years from 1 January 2006 to 31 December 2008 in Buffalo City, which includes the municipalities of East London, King William's Town and Bhisho in the Eastern Cape. Approximately 880000 people live in Buffalo City, and $25 \%$ of the population is aged between 10 and 19 years (information at www.buffalocity. gov.za).

The results could be used to develop public health guidelines to decrease the number of parasuicides in Buffalo City. They could also be used in devising training programmes in the identification of risk factors for parasuicide and early preventive measures for primary care physicians, nursing personnel, teachers and parents.

\section{Methods}

Referrals received by the East London Mental Health Unit from Frere Hospital in East London for the period 1 January 2006 - 31 December 2008 were examined. All cases of parasuicide are referred to the East London Mental Health Unit, which is the only mental health facility servicing Buffalo City. It is based at Cecilia Makiwane Hospital, Mdantsane.

The referrals in which a single agent had been used in the parasuicide were analysed and the agents categorised. The referrals in which multiple agents had been used were analysed for the commonest agent and commonest combination.

In addition to determining the agents utilised, the referrals were analysed for psychiatric diagnosis and number of parasuicide attempts. 


\section{Results}

A total of 1169 patients who had ingested substances in their parasuicide attempt were referred during the study period. Of these, 360 (31\%) were in the age group 10 - 20 years (Table I).

The categories of single agents used in parasuicide are set out in Table II.

Organophosphates were the commonest agents used in the 209 parasuicides involving a single agent (33\% of referrals) (Table III). All these referrals were recorded as the patient's first parasuicide attempt. The agent of choice in more than $50 \%$ of these cases was cattle dip. The second-commonest category of agents was antidepressants. Amitriptyline was the commonest drug. There was 1 case of fluoxetine overdose. Paraffin was the commonest volatile agent ingested.

\begin{tabular}{lccr} 
Table I. Number of referrals & & & \\
\hline & Males & Females & Total \\
\hline Single agent & 39 & 170 & 209 \\
Multiple agents & 7 & 67 & 74 \\
Unknown agent/s & 15 & 62 & 77 \\
$\quad$ Total & 61 & 299 & 360 \\
\hline
\end{tabular}

\section{Table II. Categories of agents used in parasuicide}

\begin{tabular}{|c|c|}
\hline Category & Agents \\
\hline Organophosphates & Cattle dip, pesticides \\
\hline Corrosive agents & Jik, battery acid \\
\hline Volatile agents & Paraffin, diesel, brake fluid \\
\hline Anti depressants & Amitriptyline, fluoxetine \\
\hline Anti-epileptic agents & $\begin{array}{l}\text { Carbamazepine, } \\
\text { phenytoin }\end{array}$ \\
\hline Benzodiazepines & Oxazepam, diazepam \\
\hline Asthmatic agents & Theophylline \\
\hline \multicolumn{2}{|l|}{ Paracetamol } \\
\hline \multicolumn{2}{|l|}{$\begin{array}{l}\text { Combined anti- } \\
\text { retroviral agents }\end{array}$} \\
\hline Multivitamins & Vitamin B co., folic acid \\
\hline \multicolumn{2}{|l|}{ Antibiotics } \\
\hline Neuroleptics & $\begin{array}{l}\text { Haloperidol, chlorproma- } \\
\text { zine }\end{array}$ \\
\hline \multicolumn{2}{|l|}{$\begin{array}{l}\text { Antihypertensive } \\
\text { agents }\end{array}$} \\
\hline \multicolumn{2}{|l|}{ Diabetic agents } \\
\hline \multicolumn{2}{|l|}{ Lithium carbonate } \\
\hline Analgesics & Ibuprofen \\
\hline
\end{tabular}

Analysis of the 74 cases in which multiple agents had been used revealed that co-trimoxazole was the commonest agent, followed by ibuprofen, paracetamol and tricyclic antidepressants. The commonest combinations were co-trimoxazole and ibuprofen, followed by paracetamol and tricyclic antidepressants.

Numbers of first and repeated attempts are set out in Table IV.

Of the patients referred, 4 had previously been diagnosed with major depressive disorder, 3 with bipolar mood disorder (type not specified), 2 with attention deficit hyperactivity disorder, and 1 with substance use disorder.

\section{Discussion}

The WHO estimates that worldwide 200000 suicides occur every year in the age group $15-24$ years. ${ }^{10}$ It has been demonstrated that among young people one suicide attempt raises the risk of suicide completion 15-fold, ${ }^{11}$ and several researchers have reported that the main predictor of repeated suicide attempts and eventual suicide is parasuicide. ${ }^{2,3,12-16}$ These

\begin{tabular}{lc}
$\begin{array}{l}\text { Table III. Proportions of patients using various categories of } \\
\text { agents in parasuicide }\end{array}$ & $\%$ \\
\hline Category & 33.0 \\
\hline Organophosphates & 12.4 \\
Antidepressants & 10.0 \\
Paracetamol & 9.6 \\
Asthmatic agents & 6.7 \\
Corrosive agents & 5.7 \\
Volatile agents & 4.8 \\
Benzodiazepines & 3.3 \\
Anti-epileptic drugs & 2.9 \\
Antibiotics & 2.9 \\
Multivitamins & 1.9 \\
Combined antiretroviral agents & 1.9 \\
Analgesics & 1.4 \\
Neuroleptics & 1.4 \\
Diabetic agents & 1.0 \\
Alcohol & 0.5 \\
Lithium carbonate & 0.5 \\
Antihypertensive agents &
\end{tabular}

Table IV. Numbers of first and repeat parasuicide attempts

\begin{tabular}{lr} 
& N \\
\hline 1st attempt & 346 \\
2nd attempt & 10 \\
3rd attempt & 3 \\
4th attempt & 1 \\
Total & 360 \\
\hline
\end{tabular}


findings emphasise the importance of addressing this public health concern.

The focus of the present study was to determine the common agent(s) used in parasuicide and to suggest public health programmes to address this concern.

The most common category of agents used in this study was organophosphates. The WHO reported that data from Zimbabwe showed organophosphate self-poisoning to account for threequarters of hospital admissions for suicidal behaviour. ${ }^{17}$ The same study reported that pesticides were mainly used for self-poisoning in low- and middle-income countries such as rural areas in Asia, Central and South America, Africa and the Pacific Islands, and that $60 \%$ of suicides in rural parts of China and South-East Asia were by pesticide poisoning. Eddleston et al. reported that organophosphate and carbamate pesticides caused in excess of 900 admissions and 199 deaths in Sri Lanka, ${ }^{18}$ and a study in the Islamic Republic of Iran reported that $66 \%$ of parasuicides were attributed to organophosphate poisoning. ${ }^{19}$

The findings in this study are in line with the above trends, and it is clear that development of ways to reduce parasuicide by this method is urgently needed.

The $\mathrm{WHO}$ in association with the International Association of Suicide Prevention has identified three main types of interventions, viz. safer storage of pesticides, education on their safe use, storage and disposal, and psychosocial interventions. ${ }^{17}$ These methods could potentially be employed in Buffalo City. Lockable boxes could be installed in farming households, and retailers could be educated to provide pesticide users with safety guidelines on the use, storage and disposal of pesticides. However, as Eddleston pointed out in the Sri Lanka study, ${ }^{18}$ there could be limitations to intervention involving safer storage. Buffalo City is a vast geographical area, and as in Sri Lanka most farmers live in huts, making the installation of lockable boxes difficult. Limitation of availability could be a solution, with development of national regulations to limit the quantity, type and distribution of pesticides. Such restriction may prevent a proportion of suicide attempts that are made impulsively. ${ }^{20}$

If, as Eddleston suggests, ${ }^{18}$ restriction may prove difficult, alternative methods of prevention need to be investigated.

School-based suicide prevention strategies could be utilised. Educators could be trained to identify scholars at risk and refer them to appropriate centres for further investigation and management. Mental health professionals could give both oral and written presentations on parasuicide, suicide risk factors and mental health. ${ }^{21}$ The New Zealand government has developed school-based programmes and developed guidelines for teachers and students to assess youth at risk of suicide. ${ }^{22}$ These guidelines could be revised for the Buffalo City area and utilised to address the public health concern of parasuicide. However, Portzky and Heerigen caution that school-based programmes should only be used as part of a more comprehensive strategy. ${ }^{16}$

It has been suggested that the Internet could be utilised to reduce the incidence of parasuicide, ${ }^{16,20,21}$ with websites to provide information on mental health and access to care.

Primary care physicians are the first port of call for many patients with mental illness. Programmes need to be developed to train them to recognise mental illness and suicide risk, and to treat patients appropriately or refer them for specialist care. ${ }^{22}$ As the present study shows, an important aspect of such training should include prescribing patterns, particularly in relation to tricyclic antidepressants and paracetamol. The lethality of these agents needs to be emphasised.

Public health education could form part of community-based programmes. Primary health care workers are well positioned to help with educational campaigns. They have detailed knowledge of how their community operates and what influential individuals could assist with giving impetus to a campaign.

Responsible reporting of suicide and provision of education by the media are important elements in a community-based programme. ${ }^{21,22}$ Another element could be the restriction of pack sizes of medication. ${ }^{19}$

Follow-up care after parasuicide is a potentially valuable strategy that has been successfully developed in the UK, where postcards with carefully devised supportive messages were sent to patients who had made suicide attempts. ${ }^{23}$ Improved acute, continuation and maintenance care for patients with depression could be a potential route for prevention of parasuicide and repeated attempts. ${ }^{24}$

\section{Conclusion}

Knowledge of trends and changes in methods in different countries is important in understanding the epidemiology of suicide. ${ }^{25}$

This study provides insight into the commonest agent(s) used in parasuicide in the Buffalo City area. These data could be incorporated into education programmes to train and equip primary care physicians, other health workers, educators and parents in the identification of individuals at risk and the restriction 
of access to methods. Gunnell and Frankel reported that limiting access is the strategy with most potential to reduce suicide rates. ${ }^{26}$

Accessibility of organophosphates urgently needs to be revised. The development of policies and protocols on the pack sizes of both pesticides and medication will assist in decreasing parasuicide rates in this area.

The WHO's theme for World Suicide Prevention Day in 2006 was 'With understanding new hope'. This theme provides impetus for the development of safety guidelines for the reduction of parasuicide.

\section{References}

1. World Health Organization. International Statistical Classification of Diseases and Related Health Problems. 1Oth revision. Geneva: WHO, 1992.

2. Comtois AK. A review of interventions to reduce the prevalence of parasuicide. Psychiatr Serv 2002; 53: $1138-1144$

3. Suominen K, Isometsa E, Suokas J, Haukka J, Achte K, Lonnqvist J. Completed suicide after a suicide attempt: A 37 year follow-up study. Am J Psychiatry 2004; 161: 562 563

4. Shaffer D. The suicidal adolescent. Focus 2004; 2: 517-523.

5. McNeill LY, Gillies LM, Wood FS. Fifteen year olds at risk for parasuicide or suicide: how can we identify them in general practice. Fam Pract 2002; 19(5): 464-465.

6. Centers for Disease Control and Prevention, National Center for Injury Prevention and Control. Web based injury statistics query and reporting. http://www.cdc.gov/ ncipc/wisqars (accessed 5 January 2007).

7. Barrero PAS. Preventing suicide: a resource for the family. Ann Gen Psychiatry 2008 7: 1. http://www.annnals-general-psychiatry.com/content/7/1/1 laccessed 11 March 2008)

8. Fortune AS, Hawton K. Deliberate self-harm in children and adolescents: A research update. Curr Opin Psychiatry 2005; 18(4): 401-406.
9. Fleischmann A, Bertolote MJ, Wasserman D, et al. Effectiveness of brief intervention and contact for suicide attempters: a randomized controlled trial in five countries. Bull World Health Organ 2008; 86: 657-736.

10. World Health Organization suicide rates and absolute number of suicide per country (2003). www. who. int (accessed 8 May 2008).

1 1. Basco TW. Teens at risk: A focus on adolescent suicide. Highlights of the Pediatric Academic Societies' 2006 Annual General meeting. www. medscape.com (accessed 14 July 2006).

12. Welch SS. A review of the literature on the epidemiology of parasuicide in the general population. Psychiatr Serv 2001; 52: 368-375.

13. Owens D, Horrocks J, House A. Fatal and non-fatal repetition of self harm. BrJ Psychiatry 2002; 181: 193-199.

14. Gispert M, Davis SM, Marsh L, Wheeler K. Predictive factors in repeated suicide attempts by adolescents. Hospital and Community Psychiatry 1987; 38: 390-393.

15. Cooper J, Kapur N, Webb R, et al. Suicide after deliberate self harm: A 4-year cohort study. Am J Psychiatry 2005; 162: 297-303.

16. Portzky $G$, Heeringen VK. Deliberate self harm in adolescents. Curr Opin Psychiatry 2007; 20(4): 337-342.

17. World Health Organization. Safer Access to Pesticides: Community Interventions Produced Jointly with the International Association of Suicide Prevention. Geneva: WHO, 2006.

18. Eddleston M. Sheriff RMH, Hawton K. Deliberate self harm in Sri Lanka: an overlooked tragedy in the developing world. BMJ 1998; 317: 133-155

19. Moghadamnia AA, Abdollahi M. An epidemiological study of poisoning in northern Islamic Republic of Iran. East Mediterr Health J 2002; 8(1): 88-94.

20. Beautrais A. Suicide prevention strategies. Australian e-fournal for the Advancement of Mental Health 2006; 5(1)

21. Kutcher PS, Szumilas M. Youth suicide prevention. CMAI 2008; 178(3): 282-285

22. Ministry of Education and National Advisory Committee on Health and Disability, New Zealand. Young People at Risk of Suicide: A Guide for Schools. New Zealand: Ministry of Education and National Advisory Committee on Health and Disability, March 1998.

23. Hatcher S, Owens D. Do get in touch. BMJ 2005; 331 : 788-789.

24. Mann JJ, Apter A, Bertolote J, et al. Suicide prevention strategies. JAMA 2005; 294: 2064-2074

25. Liu لJ, Lu HT. Suicide mortality trends by sex, age and method in Taiwan 1971 - 2005. BMC Public Health 2008; 8(6). http://www. pubmedcentral. nih gov (accessed 11 March 2008).

26. Gunnell D, Frankel S. Prevention of suicide: aspirations and evidence. BMJ 1994; 308: $1227-1233$. 